\title{
Viewpoint
}

\section{Viewpoint: Soil Boron Guidelines for Reclaimed Western Soils}

\section{JAMES N. BECIC}

\section{Abstract}

Regulatory guidelines establish maximum allowable boron concentrations for mine reclamation solls and overburden. However, these toxic levels are based upon research performed on boronsensitive crop species and not native plants that are naturally adapted to harsh conditions. Modifications of boron guideline parameters and laboratory analyses procedures as well as consideration of other soil interactions are suczested. A need for pertinent boron reclamation research is demonstrated.

\section{Introduction/Regulatory Requirements}

Reclamation activities remain a high priority for all western surface mining operations. Annually, thousands of hectares are re-graded, topsoiled and seeded in order to establish productive wildlife/rangeland habitat. The dilemma occurs when regulated reclamation standards, guidelines, or practices do not consider localized field conditions, yet are retained simply because there has been insufficient research done to technically support a modification. Both Wyoming (DEQ 1983) and Montana (1983) have established regulatory parameters ( $\mathrm{pH}$, conductivity, most heavy metals, etc.) and analytical procedures (numerous sampling and extraction techniques) for topsoil and overburden analyses. Of particulaar concern, for the efficient reclamation of western energy areas, are the maximum allowable boron (B) concentrations and the requirement to utilize the hot water extraction procedure for determining these concentrations.

Wyoming (DEQ 1983) considers soils "toxic" if hot water extractable B levels are present in excess of 5.0 and $8.0 \mathrm{mg} /$ liter in topsoil and overburden, respectively. If these concentrations are found, Wyoming (DEQ 1982) requires the toxic material be treated or buried under $1.2 \mathrm{~m}$ of nontoxic material. Montana (1983) limits hot water extractable $B$ in both soil and overburden to $5.0 \mathrm{mg} /$ liter. Greater levels must be treated or buried under $2.4 \mathrm{~m}$ of nontoxic material (Montana 1980).

Regardless of the regulatory requirements, the questions remain: Are these B concentration levels cause for concern when effective native plant establishment is desired? Are currently required analytical procedures for toxic soils appropriate? Are there sufficient data available to develop B standards for the mining/reclamation industry?

To thoroughly answer these questions would necessitate several years of greenhouse, laboratory, and/or field research. However, several considerations are presented in the following review.

Author is plant ecologist, Kiewit Mining and Engineering Co., 233 Kiewit Plaza Omaha, Nebr. 68131

Manuscript received August 19, 1983.

\section{Essentiality or Toxicity}

Discussion

Boron is both an essential element for higher plants as well as a potential plant toxin. Although it is required for all higher plant growth, its exact biochemical function within the plant is still speculative (Clarkson and Hanson 1980).

Plant available B is considerably less than "total" B and occurs in the soil as boric acid at neutral pH. In this form $B$ is used as an essential micronutrient (Weast 1974, Clarkson and Hanson 1980). However, only upon reaching a species specific threshold concentration of plant available B do toxicity symptoms occur.

\section{Boron Concentrations and Soil Interactions}

Most soils, depending on their origins, contain a total B content ranging from 20 to $200 \mathrm{mg}$ /liter (Berger 1965). Higher or lower levels are generally rare. Differences in B concentrations are due partially to varying parent materials on which the soils were formed but primarily to the soil types which reflect the differing climatic zones and geographic regions, i.e., podzols of Bielorussia, eutrophic peaty soils of Israel, etc. (Aubert and Pinta 1977).

Soils containing relatively high total B levels can be regarded as normal for many westen regions when 2 situations are recognized. First, vast areas of the West have soils that were derived from marine sediments, i.e., the Wyoming Basin (Hunt 1967), and naturally contain large amounts of $B$ (sea water contains from 4.0 to $5.0 \mathrm{mg} /$ liter total B). Secondly, arid and semiarid regions, regardless of their soil derivation, generally have higher B concentrations because little leaching has occurred via precipitation (Bradford 1966, Aubert and Pinta 1977, Jenkins 1981).

Several other parameters to consider when evaluating a soil's B toxicity level are the interactions of soil $\mathrm{pH}$, organic matter, and calcium (Ca) with $\mathrm{B}$.

Soil pH and its effects upon plant available B led Aubert and Pinta (1977) to make this observation: "In a basic medium, B is in the form of compounds less easily soluble. . . (hence less available to the plant). . . than those compounds formed in an acid medium." This finding was also discerned by Richardson (1979) and Bradshaw and Chadwick (1980), who concluded that in soils where the $\mathrm{pH}$ is between 8.0 and 8.5 (similar to many Westen soils), B becomes difficult for plants to absorb.

It was also noted that soils having a low organic matter content, compounded by low rainfall, trended toward having less plantavailable $B$. This trend was due to decreased biologic action (Berger 1965).

A final, potentially significant interaction is that between $B$ and $\mathrm{Ca}$. Soils in question may contain significant amounts of soluble Ca. It has been determined that "in higher plants, $\mathrm{Ca}$ ameliorates toxicities of other metal ions" (Bollard and Butler 1966). The presence of $\mathrm{Ca}$ in the soil appears to decrease both total and soluble B in plants, thereby reducing its toxicity (Stiles 1958, Berger 1965, Bradford 1966). 


\section{Laboratory Analyses}

Boron is not invariably a phytotoxin unless a substantial amount (more than is required for normal growth) is both in the soil and in a form available to the plant. If laboratory analysis indicates a $B$ concentration greater than $5.0 \mathrm{mg} /$ liter, the soil is considered toxic (DEQ 1983, Montana 1983). However, the required hot water extraction technique represents several times the B that is, in fact, available to the plant (L. Francois, US Salinity Lab., USDA-Agr. Res. Service, Riverside, Calif,, personal communication). In addition, Klusman et al. (1982), employing several different elements and procedures concluded that hot water extraction of B did not provide sufficient reproducibility to consider it a reliable method to evaluate availability of $B$.

Three recent independent laboratory analyses performed on a Western mine soil sample support the claim that hot water B testing procedures produce erratic and nonreproducible results. Conversely, saturation extracts appeared to provide stable and reliable results. (Hot water extraction in laboratories 1, 2, and 3 yielded $12.00,8.53$, and $5.43 \mathrm{mg} /$ liter $\mathrm{B}$, respectively, while the saturated paste $B$ yielded $4.10,4.55$, and $4.45 \mathrm{mg} /$ liter). Bingham (F. Bingham, Dep. of Soils and Env. Sci. Univ. Calif., Riverside, personal communication) and Schuman (G. E. Schuman, High Plains Grassland Research Station, USDA-Agr. Research Service, Cheyenne, Wyo., personal communication)both indicated that the use of a saturation extract methodology is "much better" than the hot water soluble technique, when determining plant-available B.

\section{Biologic Responses}

It is important to realize that even if the substantial problems related to soil testing methodology are disregarded, as well as all of the potential soil interactions that must have an influence on B's toxicity, it remains that species' nutrient requirements as well as B toxicity levels are not the same. Plants display.a wide range of tolerance to B (Gerloff 1963, Bradford 1966).

To date, with very few exceptions, the B-related research has been conducted utilizing introduced, nonnative, B-sensitive crop plants. Studies with agricultural crop species have generally served as the basis for regulatory agencies' maximum standard determinations for B toxicity levels. However, Schuman (personal communication) has suggested that for native plants, even $10.0 \mathrm{ppm}$ of $B$ in the saturation extract may not become a problem unless the electrical conductivity of the saturation paste extract exceeds 5 mmhos/cm. Greenhouse studies by Schuman (1969), using several varieties of tall wheatgrass (Agropyron elongatum) determined that water soluble B levels as high as 30.0 to $35.0 \mathrm{mg} /$ liter did not cause significant toxicity symptoms or reduced production. Oertli et al. (1961), utilizing nutrient solutions, found that "even $10.0 \mathrm{ppm}$ available B did not bring about a noticeable reduction of growth" when 5 turfgrass species were examined. Additionally, both Schuman (1969) and Oertli et al. (1961) observed that higher B levels were never detrimental to and often enhanced seed germination.

Recent research in the United Kingdom has established that hot water-extracted $B$ concentrations on pulverized fuel ash (PFA) are considered toxic only when levels of 21.0 to $30.0 \mathrm{mg} /$ liter are reported (Bradshaw and Chadwick 1980). Similarly, Hodgson and Townsend (1973) expect reclamation species to establish on PFA even if B concentrations are as high as $30.0 \mathrm{mg} /$ liter. Species naturally adapted to saline conditions (i.e., Atriplex spp.) "establish very satisfactorily."

Working with reclamation species on retorted oil shale in Colorado, Smith and Lindsay (1982) found that soil B concentrations of $7.2 \mathrm{mg}$ / liter for alkali sacaton (Sporobolus airoides) and fourwing saltbush (Atriplex canescens) and 10.2 and $8.5 \mathrm{mg} /$ liter for tall wheatgrass and western wheatgrass (Agropyron smithil), respectively, would be "most likely not limiting plant growth." Considering the available evidence, it appears that many native range plants have evolved under high boron levels and should not be held to the same standards as cultivated crops. Indications are that the range species, many of which are currently adapted to and growing in extremely harsh environments, should do well if used in reclamation.

\section{Conclusions and Recommendations}

1) A need exists for pertinent B research. Currently, portions of this work are being conducted by industry to determine answers to some of the questions presented in this report. However, sufficient data to justify regulatory modifications may require several years. In the interim, regulatory agencies need to develop a more flexible approach to allow mine reclamation activities to proceed (possibly on a site specific experimental basis) without undue delay.

2) Soil testing requirements need to be modified. The use of required hot water soluble methodology does not provide data that accurately reflect plant available $B$, nor is it a method that is reliably reproducible. A more appropriate testing procedure would be the use of a saturation extract.

3) Soil B levels should not be viewed as a single element in the complex soil regime. Ameliorating interactions of various soil properties, i.e., pH, texture, calcium, etc., with B must be examined before declaring that a soil has toxic levels of $B$ present.

4) Application of toxicity standards established for crop plants cannot be made "across the board" for native range species.

5) A thorough study of other state guideline parameters and procedures may be warranted, i.e., toxic burial depths, sodium adsorption ratios, various other plant toxicity levels, etc.

Recommendations presented within this report, if implemented, should allow for more efficient reclamation of mined lands and lead towards quicker re-establishment of productive rangeland/wildlife habitats.

\section{References Cited}

Aubert, H., and M. Pinta. 1977. Trace elements in soils. Elsevier Scientific Publ. Co. New York.

Berger, K. C. 1965. Introductory soils. Macmillan Co., New York.

Bollard, E. G., and G. W. Butler. 1966. Mineral nutrition of plants. Annu. Rev. Plant Phys. 17:77-105.

Bradford, G. R. 1966. Boron. p. 33-61 In: H. D. Chapman (Ed.) Diagnostic Criteria for Plants and Soils. Univ. California Div. Agr. Sci., Riverside. Bradahaw, A. D., and M. J. Chadwick. 1980. The restoration of land. Univ. California Press, Berkeley.

Clarkson, D. T., and J. B. Hanson. 1980. The mineral nutrition of higher plants. Annu. Rev. Plant Phys. 31:239-298.

DEQ 1982. Rules and regulations. Wyoming Dep. Env. Qual.- Land Qual. Dep. Env. Qual.-Land Qual. Div., Cheyenne.

DEQ 1983. Guideline no. 1: topsoil and overburden-draft. Wyoming Dep. Env. Qual. -Div., Cheyenne.

Gerloff, G. C. 1963. Comparative mineral nutrition of plants. Annu. Rev. Plant Phys. 14:107-124

Hodgson, D. R., and W. N. Townsend. 1973. The amelioration and revegetation of pulverized fuel ash. p. 247-271. In: R. J. Hutnik and G. Davis (Eds.) Ecology and Reclamation of Devastated Land. (2 vol.) Gordon and Breach, New York.

Hunt, C. B. 1967. Natural regions of the United States and Canada. W. H. Freeman and Co., San Francisco.

Jenkins, D.W. 1981. Biological monitoring of toxic trace elements. US Env. Protection Agency-Env. Mon. Syst. Lab. EPA-600/53-80-090.

Klusman, R. W., J. A. Rice, and D. G. Brown. 1982. Chemical baseline studies in the Uinta Basin, Utah. Prog. Rep. 1979-1982. Colorado School of Mines-Dep. Chem. and Geochem., Golden.

Montana. 1980. Strip and underground mine reclamation rules and regulations pursuant to the strip and underground mine reclamation act. Montana Dep. State Lands, Helena.

Montana. 1983. Soil and overburden guidelines-draft. Montana Dep. State Lands-Reclamation Div., Helena.

Oertli, J. J., O. R. Lunt, and V. B. Youngner. 1961. Boron toxicity in several turfgrass species. Agron. J. 53:262-265.

Richardson, B. Z. 1979. p. 45-58. In: USDA User Guide to Soils-Mining and Reclamation in the West. Gen. Tech. Rep. INT-68.

Schuman, G. E. 1969. Boron tolerance of tall wheatgrass. Agron. J. 61:445-447.

Smith, P.J., and W. L. Lindany. 1982. Boron toxicity in range plants grown on retorted oil shale. Colorado State Univ.-Dep. Agron., Fort Collins.

Stiles, W. 1958. Essential micro-(trace) elements. Encyclopedia of Plant Phys. 4:559-614.

Weast, R. C. 1974. Handbook of chemistry and physics-54th ed. CRC Press, Cleveland, Ohio. 